\title{
Exploring health outcomes by stochastic multicriteria acceptability analysis: An application to Italian regions
}

\author{
Raffaele Lagravinese ${ }^{\mathrm{a}}$, Paolo Liberati ${ }^{\mathrm{b}}$, Giuliano Resce ${ }^{\mathrm{c}, *}$ \\ a Department of Economics and Finance, University of Bari "Aldo Moro", Largo Abbazia Santa Scolastica, Bari 70124, Italy \\ ${ }^{\mathrm{b}}$ Department of Economics and CEFIP, Roma Tre University, Via Silvio d'Amico, Roma 77 00145, Italy \\ ${ }^{\mathrm{C}}$ Institute of Clinical Physiology, National Research Council of Italy, Italy
}

\section{A R T I C L E I N F O}

\section{Article history:}

Received 18 August 2017

Accepted 6 November 2018

Available online $\mathrm{xxx}$

\section{JEL classification:}

$\mathrm{H} 75$

I14

C44

\section{Keywords:}

OR in health services

Stochastic multicriteria acceptability

Analysis

Composite indicators

Spatial inequality

ANOGI

\begin{abstract}
A B S T R A C T
This paper introduces the Stochastic Multicriteria Acceptability Analysis (SMAA) in order to investigate the evolution of mortality rates in the Italian regions over the period 1990-2013. We propose to explore the overall outcome of health care by a Composite Index of mortality based on the combination of standardized mortality rates for seventeen different diseases. From a methodological standpoint, we propose to overcome the arbitrary nature of the weighting process, by using the SMAA, which is a methodology that allows to rank regions considering the whole set of possible vectors of weights. Moreover, we explore the spatial segregation in health using the multidimensional generalization of the Gini index, and introduce the multidimensional generalization of ANOGI. The unprecedented use of SMAA in evaluating the health sector allows to explore regional multidimensional paths beyond the order of importance given to the single dimensions. Our analysis shows that in the 24 years considered there has been no convergence path in terms of health care outcome in Italy, neither between nor within regions.
\end{abstract}

(c) 2018 Published by Elsevier B.V.

\section{Introduction}

One of the most problematic issues in evaluating the health care sector is that its outcome is multidimensional and should not be assessed by one single metric. The multidimensionality of health is not easily addressed in the evaluation literature for two main reasons. First, agreement on what indicators should be considered to evaluate the performance of the health sector is not trivial. Second, even assuming a solution for the first issue, the problem remains of how to weigh different indicators in one single index. This paper addresses these two issues by proposing a new methodology to compare the regional performance of the Italian health sector. With regard to the first point, a solution of multidimensionality is proposed by using mortality rates caused by different diseases. Mortality rates are among the most important comparable sources of information on health. Registering death is compulsory in almost all countries and the data collected are often used to monitor diseases and health status, plan health services, and compare health care systems. Furthermore, mortality rates are

\footnotetext{
* Corresponding author.

E-mail addresses: giuliano.resce@uniroma3.it, giuliano.resce@ifc.cnr.it (G. Resce).
}

often used as a robust outcome of the health care system and have been extensively used to get information about the efficiency and the effectiveness of managerial organization (Cavalieri \& Ferrante, 2016; Medin et al., 2015; Or, 2001).

Italy is an interesting case study in this respect, as it shows a large heterogeneity of mortality rates among regions, partly explained by the unresolved social-economic dualism between the Northern and Southern regions of the country. In addition, Italy has experienced a significant decentralization of the health sector since more than fifteen years, whose progress may be fruitfully investigated through the evolution of mortality rates in different areas of the country. To this purpose, a Composite Index (CI) of health outcome is proposed, calculated as a combination of 17 standardized mortality rates collected in Italian regions by ISTAT (2017) and covering the most widespread diseases.

However, the need for multidimensionality, as well as our choice of mortality rates, leaves the issue of how to weigh different indicators unresolved. From an operational perspective, the issue of how to treat multidimensional outcomes has paved the way to the development of Composite Indicators (see Costanza et al., 2016; Nardo et al., 2008). While a CI summarizes different dimensions into a single metric (OECD (2016)), the problem remains of how to assign a weight to those dimensions. The focal point in the liter- 
ature is that in order to aggregate many dimensions into one index, a choice must be made about the relative importance of each dimension, as different weights may give rise to relevant differences in the final synthetic evaluation (Cherchye, Moesen, Rogge, \& Van Puyenbroeck, 2007; Permanyer, 2011; Patrizii, Pettini, \& Resce, 2017; Costanza et al., 2016; Greco, Ishizaka, Tasiou, \& Torrisi, 2018; Greco et al., 2018).

In this context, the choice of weights by which the single outcomes are aggregated in a $\mathrm{CI}$ to evaluate the overall performance of the health sector, may affect the representativeness of the final synthetic proxy. In other words, given a differentiation either in individual health preferences (needs) or in social preferences, any single vector of weights allows to build a $\mathrm{CI}$ that, at the best, represents a satisfactory outcome only for a fraction of the population.

To overcome this issue, our proposal is to aggregate the 17 mortality rates considering the whole space of feasible vectors of weights. From a methodological standpoint, we use the idea of Greco, Ishizaka, Matarazzo, and Torrisi (2017), where the Stochastic Multicriteria Acceptability Analysis (SMAA) approach (Lahdelma, Hokkanen, \& Salminen, 1998; Lahdelma \& Salminen, 2001) is used to take into account a large sample of randomly extracted vectors of weights to rank Italian regions. According to this methodology, each region is assigned a probability of being in a given position in the national rank in terms of the composite mortality index.

This work fits into the Operational Research literature, trying to merge the innovative contributions of the SMAA with the need to deal with the multidimensionality of the mortality rate. As mentioned before, the multidimensionality of the mortality rate is a very controversial topic. So far, the various applications of SMAA have mainly concerned the environmental sector (Aertsen, Kint, Van Orshoven, \& Muys, 2011; Bottero, Ferretti, Figueira, Greco, \& Roy, 2015; Lahdelma, Salminen, \& Hokkanen, 2002), the credit market (Angilella \& Mazzù, 2015; Doumpos, Hasan, \& Pasiouras, 2017), the socio-economic performance Greco et al. (2017), transport (Menou, Benallou, Lahdelma, \& Salminen, 2010)), and the municipalities Cohen, Doumpos, Neofytou, and Zopounidis (2012). To our knowledge this is the first application of SMAA to the health sector at regional level.

This innovative approach allows to summarize a multidimensional health outcome without any assumption about the individual preferences and thus without any a priori judgement on specific vectors of weights.

Our results show a pervasive and persistent territorial divide in the regional health care in Italy, regardless of the set of weights that is used to aggregate mortality rates. Evidence is also provided that the spatial segregation is significant both between and within regions. These results are confirmed using both the multidimensional Gini index, originally proposed in Greco et al. (2017), and the multidimensional generalization of ANOGI (Liberati, 2015; Yitzhaki, 1994), introduced for the first time in this study.

The rest of the paper is organized as follows: Section 2 describes the Italian National Health Service; Section 3 introduces the dataset, the SMAA methodology, the multidimensional Gini Index, and the multidimensional ANOGI; Section 4 discusses results; and Section 5 concludes.

\section{The Italian health care system}

The Italian National Health Service (NHS), introduced in 1978, is a universal health care system providing comprehensive health insurance coverage and uniform health benefits to the whole population. Since its introduction, and like other European countries the Italian NHS has undergone important reforms to decentralize health management and policy responsibilities to the sub-layers of government Turati (2013). Italy is divided into 20 regions: 15 are ordinary statute regions (OSRs) and 5 are special statute regions $(\mathrm{SSRs})^{1}$. After one of the most important federal reforms (Legislative Decree 56/2000), each region is responsible for the organization of the health system, following the guidelines defined by the central government.

A first step towards the organization of a fiscal decentralized system was represented by the introduction of two regional taxes in 1998: the regional tax on productive activities (RTPA) and the regional personal income tax (RPIT). The revenue from these two taxes covers a significant share of the cost of the national health system. However, given the heterogeneity of the Italian regions in economic, social and demographic terms, these two regional taxes are not sufficient to finance the whole health system. Since both RTPA and RPIT are positively related to per capita GDP and their revenues greatly vary among Italian regions (Lagravinese, Liberati, \& Sacchi, 2018), this requires an equalization fund (funded by a system of VAT revenue-sharing and by the tax on petrol) to compensate for different regional fiscal capacities (Cavalieri \& Ferrante, 2016).

A second step towards the decentralization of the health system was made in 2001, after the definition of the Essential Levels of Health Service (LEA, "Livelli Essenziali di Assistenza") and a Constitutional reform that assigned the responsibility for the provision of health to regions, at the same time keeping the power to regulate and to finance health functions at the central level (Cappellaro, Fattore, \& Torbica, 2009; Ferrario \& Zanardi, 2011). LEA is not a problematic issue per se; it is a list of health care services that the central government requires to be guaranteed in all regions. ${ }^{2}$ However, the separation of financing responsibilities from expenditure responsibilities in the provision of LEA, and before LEA in the provision of uniform levels of service, has provided a non-negligible incentive to the uncontrolled growth of Italian health expenditure and has historically contributed in creating bailing out expectations in regional behaviour (Liberati, 2003), in a context of often inadequate regional health governance and accountability (Carinci, Caracci, Di Stanislao, \& Moirano, 2012).

The solution to the problems of the regional health sectors, however, should not disregard the fact that Italy is historically a dual country in many dimensions. In the Southern regions, on average, socioeconomic conditions, social capital and administrative behaviour are of poorer quality than in the Northern regions. Significant differences also exist in GDP per capita (on average 31,045 euros in the Centre-North and 17,436 euros in the South), unemployment rates (9.1\% in the Centre-North and $19.7 \%$ in the South), and deprivation index (15.3 point in the Centre-North and 40.8 point in the South). In 2013, per capita public expenditure on health amounts to 1816 euros (see Table 1), but their level varies widely, due to both different socio-economic conditions and different management strategy in regional health systems. While the North and the Centre are clearly above the average national value (1839 and 1877 euros, respectively), the South is below the same average (1727 euros) despite the high level of spending in Molise (2210 euros), which is partly due to anomalies like the huge budget deficit and the degree of corruption. In the Northern regions, Valle d'Aosta registers the highest per capita expenditure (2145 euros), followed by Trentino ${ }^{3}$ (2085 euros), and Friuli (2040 euros). Per capita expenditure is lower in Veneto (1710 euros), Campania (1668) and Sicilia (1719 euros).

The trend of mortality rates also reflects the dualism of the country. The mortality rates in 2013 for all regions fell in compar-

\footnotetext{
1 The difference between OSRs and SSRs is mostly linked to the way they are financed.

2 LEA list was recently updated by a ministerial decree in 2017.

3 Note that the value of Trentino is given by the average of the two autonomous provinces of Bolzano and Trento.
} 
Table 1

Health expenditure and mortality rate in Italy (Before and after the decentralization).

\begin{tabular}{|c|c|c|c|c|c|c|c|c|c|}
\hline \multirow[t]{2}{*}{ Region } & \multicolumn{3}{|c|}{ Health expenditure per capita (Current price) } & \multicolumn{3}{|c|}{ Mortality rate (Standardized) Men } & \multicolumn{3}{|c|}{ Mortality rate (Standardized) Women } \\
\hline & 1990 & 2001 & 2013 & 1990 & 2001 & 2013 & 1990 & 2001 & 2013 \\
\hline Piemonte & 699 & 1271 & 1828 & 162.18 & 129.92 & 100.17 & 100.81 & 79.14 & 65.18 \\
\hline Valle d'Aosta & 751 & 1491 & 2145 & 171.8 & 141.47 & 98.43 & 90.07 & 83.29 & 61.58 \\
\hline Lombardia & 713 & 1273 & 1818 & 172.68 & 130.32 & 94.74 & 98.98 & 75.58 & 60.81 \\
\hline Trentino A.A. & 740 & 1474 & 2085 & 157.64 & 124.27 & 90.14 & 88.8 & 68.36 & 57.12 \\
\hline Veneto & 762 & 1279 & 1710 & 161.45 & 122.58 & 95.31 & 91.61 & 70.86 & 60.27 \\
\hline Friuli V.G. & 762 & 1355 & 2040 & 171 & 129.76 & 100.17 & 94.49 & 75.26 & 64.17 \\
\hline Liguria & 901 & 1508 & 2003 & 163.51 & 128.44 & 102.15 & 96.71 & 78.37 & 65.42 \\
\hline Emilia-R. & 859 & 1337 & 1860 & 148.85 & 118.03 & 92.25 & 91.37 & 72.41 & 62.15 \\
\hline Toscana & 780 & 1341 & 1805 & 147.06 & 118.52 & 94.02 & 91.29 & 72.4 & 61.67 \\
\hline Umbria & 754 & 1306 & 1840 & 144.25 & 118.59 & 93.8 & 91.87 & 71.9 & 59.12 \\
\hline Marche & 845 & 1319 & 1760 & 140 & 112.37 & 92.25 & 87.73 & 67.77 & 58.73 \\
\hline Lazio & 785 & 1434 & 1962 & 153.83 & 127.59 & 98.08 & 98.47 & 80.17 & 65.02 \\
\hline Abruzzo & 703 & 1385 & 1736 & 144.28 & 118.52 & 97.99 & 94.74 & 69.58 & 63.23 \\
\hline Molise & 691 & 1377 & 2210 & 128.25 & 118.64 & 97.09 & 90.94 & 72.98 & 61.59 \\
\hline Campania & 687 & 1301 & 1668 & 163.32 & 139.34 & 114.13 & 116.47 & 90.32 & 74.9 \\
\hline Puglia & 670 & 1232 & 1764 & 145.96 & 119.18 & 95.76 & 99.09 & 77.64 & 63.7 \\
\hline Basilicata & 584 & 1158 & 1829 & 144.71 & 122.96 & 98.97 & 98.26 & 75.87 & 62.28 \\
\hline Calabria & 607 & 1263 & 1709 & 141.73 & 117.48 & 99.41 & 98.71 & 81.22 & 65.39 \\
\hline Sicilia & 692 & 1163 & 1719 & 155.6 & 124.58 & 103.83 & 113.28 & 87.28 & 70.52 \\
\hline Sardegna & 686 & 1304 & 2043 & 143.72 & 127.76 & 98.16 & 95.47 & 76.53 & 60.04 \\
\hline Italy & 734 & 1303 & 1816 & 156.29 & 125.18 & 98.22 & 98.32 & 77.17 & 64.01 \\
\hline North & 757 & 1310 & 1839 & 163.24 & 126.37 & 95.97 & 95.99 & 74.83 & 62.04 \\
\hline Centre & 789 & 1379 & 1877 & 148.44 & 121.43 & 95.75 & 93.67 & 74.89 & 62.62 \\
\hline South & 667 & 1279 & 1727 & 150.54 & 126.17 & 103.48 & 104.45 & 81.7 & 68.01 \\
\hline
\end{tabular}

Source: Authors' elaboration on ISTAT (2017).

ison with 1990 and 2001. However, while in 1990 and 2001 the mortality rate was on average higher in the Northern regions, the trend reversed in 2013, with significantly higher rates in the South (of about 5 points with respect to the national average), and peaks in Campania and Sicilia. Further, a significant gender gap can be traced in mortality rates in all regions. ${ }^{4}$ Among men, the mortality rate is, on average, 34\% higher than among women in 2013.

\section{The empirical model}

\subsection{The multidimensionality of health outcome}

With the aforementioned decentralization process, the Italian regions have the organizational responsibility of the healthcare system with the ultimate aim of reducing the various causes of death and increasing the life expectancy of their resident population. The National Institute of Statistics, collects several aspects of the multidimensionality of health outcome at the regional and provincial level into the "Health for All" dataset ISTAT (2017). In particular, this database contains the standardized regional mortality rates for seventeen different diseases ${ }^{5}$, along the intervals 1990-2003 and 2006-2013. The advantage of using standardized mortality rates basically consists of isolating the influence of a different number of individuals in sub-groups of populations Julious, Nicholl, and George (2001). Yet, the identification of the output of the health system is a big issue in the economic and operational literature, because, in principle, it would require to extend the set of possible measures, by including - for example - the increase in the length of life, improvements in quality of life, health population status, and the equity of access to services. However, the choice of mortality rates has been driven by the fact that, for many aspects, they are considered better than other outcomes as a proxy

\footnotetext{
${ }^{4}$ Gender gap is also observed in other European countries (see OECD (2016)).

5 The 17 mortality rates are: infectious disease; AIDS; tuberculosis; cancer; disease endocrine gland; diabetes mellitus; blood disorders; mental disorders; nervous system disease; disease circulatory system; disease respiratory system; disease digestive system; disease genitourinary system; complications of pregnancy; skin condition; disease muscular system; unclearly defined symptoms.
}

for the health care sector, and that they are widely adopted as health indicator (see Cavalieri \& Ferrante, 2016; Deaton \& Lubotsky, 2003; Medin et al., 2015; Or, 2001; Sen, 1998). Furthermore, mortality rates can better capture the short run changes that occurred in the health care system during the time span of our analysis, compared with life expectancy, blood pressure, patient experience measures, that are instead believed to reflect long run changes. Finally, but not less relevant, mortality rates are not subject to statistical manipulations as are data on life expectancy and avoidable mortality (Porcelli, 2014).

In our dataset (ISTAT, 2017) the sub-groups are defined in terms of age and sex. The descriptive statistics for the regional standardized mortality rates are reported in Table 2. It is worth noting that the Italian trend of standardized mortality rates from 1990 to 2013 is on average decreasing for all mortality rates, at relatively higher levels in cancer and circulatory system diseases.

\subsection{The composite index}

From a methodological perspective, multidimensional information can be combined into one index by Multiple Criteria Decision Analysis (MCDA, Greco, Figueira, \& Ehrgott, 2016; Ishizaka \& Nemery, 2013). In the MCDA problem, a set of alternatives $A$ (regions) is evaluated on a set of criteria G's (the seventeen standardized mortality rates):

$A=\left\{a_{1}, \ldots, a_{m}\right\}$

$G=\left\{g_{1}, \ldots, g_{n}\right\}$

The individual function that aggregates standardized mortality rates can be assumed as the weighted sum of the seventeen mortality rates multiplied by the weights associated to each of the seventeen diseases. Given the individual preferences, for each region $a_{k} \in A$, we can estimate the following individual CI of mortality depending on a set of weights $w$ :

$C I\left(a_{k}, w\right)=\sum_{i=1}^{n} w_{i} g_{i}\left(a_{k}\right)$ 
Table 2

Standardized mortality rates.

\begin{tabular}{llllll}
\hline Cause of mortality & Coverage & Min & Max & Mean & Std. Dev. \\
\hline AIDS & $1990-2003,2006-2013$ & 0.000 & 1.775 & 0.260 & 0.306 \\
Complications of pregnancy & $1990-2003,2006-2013$ & 0.000 & 0.270 & 0.012 & 0.025 \\
Diabetes mellitus & $1990-2003,2006-2013$ & 1.215 & 6.985 & 3.028 & 1.034 \\
Mental disorders & $1990-2003,2006-2013$ & 0.145 & 4.020 & 1.603 & 0.551 \\
Disease digestive system & $1990-2003,2006-2013$ & 2.535 & 9.365 & 4.699 & 1.361 \\
Disease respiratory system & $1990-2003,2006-2013$ & 4.800 & 14.920 & 7.247 & 1.449 \\
Disease endocrine gland & $1990-2003,2006-2013$ & 1.410 & 7.265 & 3.580 & 1.032 \\
Infectious disease & $1990-2003,2006-2013$ & 0.130 & 2.325 & 0.891 & 0.448 \\
Skin condition & $1990-2003,2006-2013$ & 0.000 & 0.500 & 0.127 & 0.058 \\
Blood disorders & $1990-2003,2006-2013$ & 0.135 & 2.355 & 0.634 & 0.375 \\
Disease circulatory system & $1990-2003,2006-2013$ & 24.335 & 69.875 & 42.287 & 9.958 \\
Disease muscular system & $1990-2003,2006-2013$ & 0.050 & 0.995 & 0.385 & 0.123 \\
Nervous system disease & $1990-2003,2006-2013$ & 1.085 & 4.405 & 2.667 & 0.608 \\
Unclearly defined symptoms & $1990-2003,2006-2013$ & 0.485 & 6.040 & 1.604 & 0.888 \\
Tuberculosis & $1990-2003,2006-2013$ & 0.030 & 0.170 & 0.100 & 0.043 \\
Cancer & $1990-2003,2006-2013$ & 20.560 & 40.725 & 29.422 & 4.067 \\
Disease genitourinary system & $1990-2003,2006-2013$ & 0.680 & 2.385 & 1.509 & 0.293 \\
\hline
\end{tabular}

Source: ISTAT (2017).

where $w_{i}$ reflect the importance that the citizen gives to disease $i$, and $g_{i}\left(a_{k}\right)$ is the mortality rate in the region $a_{k}$ for the disease $i$. The main problem is that the order of importance may change among people and even among different policy-makers, which implies that one single vector of $w$ that is representative for the whole population does not exist.

The simplest way would be to assume that each citizen gives the same importance to each disease, i.e., $w_{1}=w_{2}=w_{3}=\cdots=w_{i}$. This method, while representing one of the most popular ways to build composite indices (see: Floridi, Pagni, Falorni, \& Luzzati, 2011; Greco et al., 2018), is rather unsatisfactory and implicitly assumes the existence of an unrealistic 'representative agent' evaluating the performance of health care. When assuming that preferences are different, as they are, weights should also be different. This introduces the problem of which is the best set of weights, when excluding both a priori information and a set of weights reflecting a merit good approach by part of the policy-maker. This issue is particularly relevant in the evaluation of the performance of public services, as by changing the set of weights the ranking of regions in the health outcome may change.

\subsection{Stochastic Multicriteria Acceptability Analysis}

In the MCDA literature, this question was addressed with the SMAA proposed in Lahdelma et al. (1998), and generalized in Lahdelma and Salminen (2001) SMAA was specifically developed for situations where weights are unknown. In order to embody unknown preferences on the weights assigned to each dimension, SMAA considers the probability distributions $f_{W}(w)$ in the set of the feasible weights $W$ defined as:

$W=\left\{\left(w_{1}, \ldots, w_{n}\right) \in R_{+}^{n}, \quad w_{1}+\cdots+w_{n}=1\right\}$

The set of feasible weights is a $(n-1)$ dimensional simplex. Total lack of knowledge about weights is represented by a uniform weight distribution in the set of feasible weights $\mathrm{W}$. In detail, to rank regions according to the composite index of mortality rates, the rank is defined as an integer from 1 to $m$ (the number of regions). Starting from the probability distributions $f_{\chi}(\xi)$ on $\chi$, where $\chi$ is the evaluation space (in our case the space of the values assumed by the mortality rates $g_{i} \in G$ ) (Lahdelma \& Salminen, 2001 ) introduce a ranking function relative to the region $a_{k}$ :

$\operatorname{rank}(k, \xi, w)=1+\sum_{h \neq k} \rho\left[C I\left(\xi_{h}, w\right)>C I\left(\xi_{k}, w\right)\right]$

where $\rho$ (true $)=1$, and $\rho$ (false $)=0$. In words, the rank of region $a_{k}$, for a vector of weights $w$, is one plus how many times the weighted sum of mortality rates of $a_{k}\left(C I\left(\xi_{k}, w\right)\right)$ is dominated by the weighted sum of mortality rates of the other regions $\left(C I\left(\xi_{h}, w\right)\right)$. Thus, the value assumed by the variable "rank" in Eq. (5) is one plus the number of regions that performs worse than region $k$ in terms of mortality rates. It follows that the higher the value of "rank" the better the performance of the region.

Accordingly, for each region $a_{k}$ and for each value that can be taken by mortality rates $\xi \in \chi$, SMAA computes the set of weights for which region $a_{k}$ assumes rank $r$ :

$W_{k}^{r}(\xi)=\{w \in W: \operatorname{rank}(k, \xi, w)=r\}$

From Eq. (6), one can then compute the rank acceptability index, which is a relative measure of (6). In symbols ${ }^{6}$ :

$b_{k}^{r}=\int_{\xi \in \chi} f_{\chi}(\xi) \int_{w \in W_{k}^{r}(\xi)} f_{W}(w) d w d \xi$

Eq. (7) gives the probability that the region $a_{k}$ has the $r$ th position in the ranking. In other words, $b_{k}^{r}$ is the ratio of the number of the vector of weights by which region $a_{k}$ gets rank $r$ to the total amount of feasible weights (i.e., the number of cases in which region $a_{k}$ achieves the rank $r$ on the total number of cases considered). From a computational perspective, the multidimensional integrals are estimated by using Monte Carlo simulations. To this purpose, our estimates are the result of 100,000 random extractions of vectors $w$ from a uniform distribution in $W{ }^{7}$

\subsection{The multidimensional generalization of the Gini index}

The previously defined rank acceptability index $b_{k}^{r}$ can be used to define a multidimensional generalization of the Gini index, as suggested by Greco et al. (2017). This result is obtained by first defining the upward cumulative rank acceptability index of rank $l$, i.e., the probability that the region $a_{k}$ has a rank $l$ or higher (Angilella, Corrente, Greco, \& Słowiński, 2016). In symbols:

$b_{k}^{\geqslant l}=\sum_{s=l}^{m} b_{k}^{s}$

Given (8), one can calculate a Gini index in the traditional way, a measure that we can refer as to the Gini index of the upward

\footnotetext{
6 The following definition of $b_{k}^{r}$ is the general definition of the rank acceptability index proposed by Lahdelma and Salminen (2001). In this study, we do not consider the probability distribution $f_{\chi}(\xi)$ because the values taken by the considered criteria are the mortality rates provided by ISTAT (2017).

7 Tervonen and Lahdelma (2007) shows that 10,000 extractions are enough to get an error limit of 0.01 with a confidence interval of $95 \%$.
} 
cumulative rank acceptability index of rank $l$ (Greco et al., 2017):

$G^{\geqslant l}=\frac{\sum_{h=1}^{m} \sum_{k=1}^{m}\left|b_{h}^{\geqslant l}-b_{k}^{\geqslant l}\right|}{2 m l}$

Eq. (9) measures how the probabilities of attaining rank $l$ or higher are concentrated among the considered regions. For each $l$, the higher $G^{\geq l}$ the more concentrated is the probability to be above this rank in terms of the composite index of mortality. More specifically, $G^{\geq l}$ measures the dispersion of the probability that each region may have in occupying rank $l$ or higher. If this probability were the same for all regions, $G^{\geq l}$ would be zero. A high level of $G^{\geq}$, instead, would signal that this probability is heavily concentrated in few regions, as it would be the case if there were great differences in the health outcome.

Using the same rationale, the downward cumulative rank acceptability index of position $l$ for region $a_{k}$ is:

$b_{k}^{\leqslant l}=\sum_{s=1}^{l} b_{k}^{s}$

Analogously to (9), the Gini index of the probability to attain rank $l$ or lower can be defined as:

$G^{\leqslant l}=\frac{\sum_{h=1}^{m} \sum_{k=1}^{m}\left|b_{h}^{\leqslant l}-b_{k}^{\leqslant l}\right|}{2 m(m-l+1)}$

The interpretation is the same as before. For each $l$ the higher $G \leq l$ is the more concentrated is the probability to be below this rank in terms of the composite index of mortality. According to Greco et al. (2017), $G^{\geq l}$ and $G^{\leq l}$ are generalizations of the Gini index because they take into account all the possible vectors of weights rather than being based on one specific vector, as is the case in most of the multidimensional concentration indices proposed in literature (Savaglio, 2006; Weymark, 2006).

\subsection{The multidimensional generalization of ANOGI}

As a further step of the analysis, health inequality is analysed not only between regions but also within them. As it is well known, however, the Gini index is not perfectly decomposable in between- and within-inequality (Pyatt, 1976). To overcome this problem, we extend the Analysis of Gini (ANOGI) as proposed by Yitzhaki (1994) and further developed by Liberati (2015), to the decomposition of (9) and (11).

As argued by Yitzhaki and Schechtman (2013); 481-482), the general idea behind ANOGI is to decompose the measure of variability into "inter-groups" and "intra-groups" sources. To some extent, the structure of ANOGI is identical to the structure of the Analysis of Variance (ANOVA) when the distribution of different subgroups is perfectly stratified, i.e., they do not overlap. When they overlap, instead, it implies that most of the variability is attributed to the intra-group component. Putting it differently, ANOGI is a measure of the quality of a classification according to a given index; if the chosen index significantly separate subgroups (i.e., there is no overlapping), the quality of classification is high. The opposite holds true (low quality of classification) if overlapping would be high. Because of these properties, ANOGI can be used for various applications: to detect whether two sub samples represent the same universe when using survey data (Frick, Goebel, Schechtman, Wagner, \& Yitzhaki, 2006); to explore the degree of integration of immigrants and ethnic groups into a society (Yitzhaki \& Schechtman, 2009); to decompose income inequality (Liberati, 2015; Milanovic \& Yitzhaki, 2002). Consider for example different income distributions and the index provided by average income. If distributions were perfectly stratified - i.e., all rich people belong to a country, while all poor people belong to another country - average income would perfectly identify the group each individual belongs to. But if the two distributions were perfectly overlapping, average income would fail to provide a high quality classification, as the same average income could identify individuals belonging to either group.

Thus, for our purposes, ANOGI is particularly useful, as it will convey information on whether mortality rates (and the associated probabilities) could provide a high quality classification of the performances of regional health systems. In other words, it will allow to understand the extent to which the Northern and the Southern regions of Italy can be considered as separate and stratified groups according to the $\mathrm{CI}$ of mortality rates.

The main feature of ANOGI is that a residual term (overlapping) is part of the decomposition of income inequality, which can be interpreted as the measure of how the regional distributions are intertwined. In particular, the ANOGI decomposition proposed in Liberati (2015) allows to split total within inequality in a term representing the standard within inequality without overlapping and a term representing the impact of overlapping in within inequality. Furthermore, ANOGI also allows to distinguish the part of the between-inequality that is due to overlapping.

Adapting the procedure by Liberati (2015), the following decomposition will be used for the case of the Gini index of the upward cumulative rank:

$$
\begin{aligned}
G^{\geqslant l}= & \sum_{i} \underbrace{s_{i} G_{i}^{\geqslant l} p_{i}}_{\text {Standard WI }}+\underbrace{\sum_{i} s_{i} G_{i}^{\geqslant l} \sum_{j \neq i} p_{j} O_{j i}^{\geqslant l}}_{\text {Impact of overlapping on WI }} \\
& +\underbrace{G_{B p}^{\geqslant l}}_{\text {Standard BI }}+\underbrace{\left(G_{B}^{\geqslant l}-G_{B p}^{\geqslant l}\right)}_{\text {Impact of overlapping on BI }}
\end{aligned}
$$

Before interpreting Eq. (12) it is worth discussing the meaning of the term $O_{j i}^{\geqslant l}$. In principle, this term can be interpreted as an overlapping term (i.e., as a measure of how the distribution of probabilities in region $i$ overlaps with the distribution of probabilities in another region $j$ ). If no provinces in region $j$ lie in the range of the distribution of probabilities in region $i$, region $i$ would be a perfect stratum and $O_{j i}^{\geqslant l}=0$. Thus, if all regions were perfect stratums, the whole second term on the right-hand side of (12) would collapse to zero. This unlikely assumption would mean that all regions would show a within distribution of probabilities that is not within the range of any other region. The general case, instead, is to observe overlapping among probabilities of some provinces in one region and those of other provinces in other regions, which means that one can expect $O_{j i}^{\geqslant l}>0$. Furthermore, $O_{j i}^{\geqslant l} \leqslant 2$, and the maximum value is achieved when all probabilities associated to region $j$ that are located in the range of $i$ are concentrated at the mean of the distribution $i$. This implies that the probabilities of region $j$ would separate the probabilities of region $i$ that are below the average from those that are above the average. Finally, it is worth noting that the higher $O_{j i}^{\geqslant l}$, the lower will be $O_{i j}^{\geqslant l}$, which is obtained by changing the region used as a baseline. This is intuitive, as the more the probabilities of region $j$ are included in the range of the distribution of probabilities in region $i$, the less the probabilities of region $i$ are expected to be included in the range of region $j$.

In symbols, the overlapping coefficient is defined as:

$O_{j i}=\frac{\operatorname{cov}\left(b_{i}^{\geqslant l}, F_{j}\left(b^{\geqslant l}\right)\right.}{\operatorname{cov}\left(b_{i}^{\geqslant l}, F_{i}(b \geqslant l)\right.}$

where the numerator is the covariance between the upward cumulative rank acceptability indices of at least rank $l$ of region $i$, and their ranking in the distribution of the upward cumulative rank acceptability indices in region $j$; while the denominator is the covariance between the same upward cumulative rank acceptability indices and their ranking within each region. 
This definition helps to understand the meaning of Eq. (12). The first term on the right-hand side is the standard within-region inequality (WI) in the absence of overlapping, obtained as the sum of the inequality among provinces of each region, where $s_{i}$ is the probability of region $i$ to be in rank $l$ or higher and $p_{i}$ is the share of population of region $i$. The second term, instead, would be the impact of overlapping on within inequality, driven by the contribution of the overlapping index of each region with all other regions weighted by their population shares.

In the context of the measurement of health outcomes in the Italian regions, overlapping is particularly important, as it gives information on the quality of ranking regions according to mortality rates. In particular, it reveals whether the variable chosen to rank regions is meaningful to describe the performance of the health sector.

The last two terms of Eq. (12), instead, deal with the betweenregion inequality (BI). The term $G_{B p}^{\geqslant l}=\frac{2 \operatorname{cov}\left(\bar{b}_{i} \bar{F}_{i}(b)\right)}{\bar{b}}$ is based on the between inequality as originally defined by Pyatt (1976), where the covariance is between the mean probability of each region $\bar{b}_{i}$ and its rank in the distribution of the mean probabilities of all regions $\bar{F}_{i}(b)$. In this case, the mean probability $\bar{b}_{i}$ is the average probability of all possible ranks of each region; while $\bar{F}_{i}(b)$ is the position of that average probability in the distribution of the average probabilities of all regions. This definition would imply that $G_{B p}=0$ when all the mean probabilities are equal. According to Yitzhaki and Lerman (1991), one can alternatively define $G_{B}^{\geqslant l}=\frac{2 \operatorname{cov}\left(\bar{b}_{i} \bar{F}(b)\right)}{\bar{b}}$, which is based on the covariance between the mean probability of each region $\bar{b}_{i}$ and the average rank of all regional probabilities in the national distribution of probabilities $\bar{F}(b) .^{8}$ In this case, $G_{B}^{\geqslant l}=0$, implies that the average rank of all regions in the national distribution would be equal.

If regions were perfectly stratified, $G_{B}^{\geqslant l}=G_{B p}^{\geqslant l}$. This implies that in the absence of the overlapping of probabilities, betweeninequality would be uniquely defined by $G_{B p}^{\geqslant l}$. With overlapping, $G_{B}^{\geqslant l}-G_{B p}^{\geqslant l}<0$, which can be used as an indicator of the reduction in between inequality caused by the overlapping of probabilities.

It is clear from above that with perfect stratification the decomposition (12) would collapse to $G^{\geqslant l}=\sum_{i} \underbrace{s_{i} G_{i}^{\geqslant l} p_{i}}+\underbrace{G_{B p}^{\geqslant l}}$ i.e., Standard WI Standard BI

to a decomposition of the Gini index in within and between inequality without any residual component.

With the same rationale, one can decompose the downward cumulative Gini coefficient as follows:

At this stage, an example may help clarify the functioning of the ANOGI decomposition. From a dataset made of 103 towns distributed in 20 regions (See Table 11 in Supplementary Material), consider a subset with three regions (Region 1, 2, 3 in Table 11) and in each of which consider three towns (A, B, C in Table 11) with their own health system. Assume 100,000 set of weights and also assume that the distribution of probabilities in region 1 is as follows: (a) town $1 \mathrm{~A}$ is among the 20 best performers for 134 times; (b) town $1 \mathrm{~B}$ is among the 20 best performers for 301 times; (c) town $1 \mathrm{C}$ is among the 20 best performers for 71,063 times. In region 2, one can assume the following distributions: (a) town $2 \mathrm{~A}$ is among the 20 best performers for 18,006 times; (b) town $2 \mathrm{~B}$ is never among the 20 best performers; (c) town $2 \mathrm{C}$ is never among the 20 best performers. Finally, in region 3: (a) town 3A is among the 20 best performers for 4251 times; (b) town $3 \mathrm{~B}$ is among the 20 best performers for 3568 times; (c) town $3 \mathrm{C}$ is among the 20 best performers for 3793 times.

\footnotetext{
${ }^{8}$ According to what argued by Yitzhaki and Schechtman (2013) (484), $G_{B p}^{\geqslant l}$ is a Gini coefficient, while $G_{B}^{\geqslant l}$ is not. By construction $G_{B}^{\geqslant l}<G_{B p}^{\geqslant l}$.
}

As can be seen, this example gives rise to a distribution of probabilities among towns in different regions. It is also worth noting that in the considered subset the two worst performers are towns $2 \mathrm{~B}$ and $2 \mathrm{C}$; the two worst performers above $2 \mathrm{~B}$ and $2 \mathrm{C}$ are towns $1 \mathrm{~A}$ and $1 \mathrm{~B}$ in region 1 ; but in the same region, there is also the best performer (town $1 \mathrm{C}$ ). This intertwining of performances means that regions are not perfectly stratified, as the rank of some towns in one region is within the range of other towns in other regions. In particular, by applying ANOGI to the previous subsample, one obtains a Gini index of 0.77 , which describes the inequality of the distribution of probabilities in towns. This means that inequality would be high among the towns that may be the best performers. However, the most interesting implication of ANOGI is the overlapping term, in particular the overlapping matrix of regions that would be provided by the decomposition, which is as follows:

\begin{tabular}{llll}
\hline & 1 & 2 & 3 \\
\hline 1 & 1.00 & 0.66 & 1.99 \\
2 & 1.33 & 1.00 & 2.00 \\
3 & 0.00 & 0.00 & 1.00
\end{tabular}

To explain the meaning of this unconventional index of overlapping one can consider the extreme cases. In particular, $O_{1,3}=0$, which means that no towns of region $A$ lie in the range of towns in region 3 . Indeed, according to the previous example, the probabilities of towns in region 1are either below or above the probabilities of towns in region 3 , which means that region 1 is a perfect stratum. On the other hand, $\mathrm{O}_{3,2}=2$, which means that all probabilities associated to region 3 are located in the range of region 2 . Thus, the overlapping term (and the associated matrix) gives information on how the distribution of probabilities attached to any town are intertwined among regions. As a counterexample, one can consider what happens when, leaving the others unchanged, town 1 is given a probability of 400 times and town 2Ais given a probability of 100 times $^{9}$. Performing ANOGI, in this case, would give rise to overlapping terms all equal to zero (when $\mathrm{i} \neq \mathrm{j}$ ), which means that all regions are perfect stratum in the sense that each town, in its region, has a probability that is not in the range of probabilities of towns in other regions. This would imply that the quality of classification according to mortality rates is high, as the lower the overlapping the higher the between-region inequality (in this last example it would be $97 \%$ of the total inequality of probabilities).

With the same rationale, one can decompose the downward cumulative Gini coefficient as follows:

$$
\begin{gathered}
G^{\leqslant l}=\sum_{i} \underbrace{s_{i} G_{i}^{\leqslant l} p_{i}}_{\text {Standard WI }}+\underbrace{\sum_{i} s_{i} G_{i}^{\leqslant l} \sum_{j \neq i} p_{j} O_{j i}^{\leqslant l}}_{\text {Impact of overlapping on WI }} \\
+\underbrace{G_{B p}^{\leqslant l}}_{\text {Standard BI }}+\underbrace{\left(G_{B}^{\leqslant l}-G_{B p}^{\leqslant l}\right)}_{\text {Impact of overlapping on BI }}
\end{gathered}
$$

The terms in (14) have the same meaning as before, but with respect to the probabilities of having rank $l$ or lower.

\section{Results}

In our analysis, SMAA is applied to the regional standardized mortality rates in the period 1990-2013. In what follows, ranks are thus defined in terms of the composite mortality. As previously discussed, for each region the higher the value of the rank, the higher the health outcome. The focus will be on four aspects: (a) the calculation of the composite index of mortality rates using constant weights; (b) how the rank changes using uniform random

\footnotetext{
9 See fourth column in Table 11 (Supplementary Material).
} 
Table 3

Moving average in Rank by the simple arithmetic mean of standardized mortality rates.

\begin{tabular}{lllll}
\hline Region & $1990-1995$ & $1996-2001$ & $2002-2007$ & $2008-2013$ \\
\hline Piemonte & 6.67 & 6.33 & 4.5 & 4.83 \\
Valle d'Aosta & 6.83 & 2.5 & 3.75 & 10.33 \\
Lombardia & 3.67 & 5.5 & 9.5 & 12.67 \\
Trentino A.A. & 15 & 16.17 & 15.75 & 19.83 \\
Veneto & 10.83 & 13.17 & 13.75 & 15 \\
Friuli V.G. & 5.17 & 8.5 & 8 & 7.5 \\
Liguria & 6 & 6.83 & 6.5 & 4.17 \\
Emilia-R. & 18.33 & 18.33 & 16.75 & 16.5 \\
Toscana & 16 & 16 & 15.5 & 13.83 \\
Umbria & 15.67 & 16.83 & 18.5 & 17.33 \\
Marche & 19.83 & 20 & 20 & 19.17 \\
Lazio & 6.83 & 6 & 5.75 & 6.83 \\
Abruzzo & 14.67 & 16.5 & 15.5 & 12 \\
Molise & 18 & 14.67 & 14.75 & 11.67 \\
Campania & 1 & 1 & 1 & 1 \\
Puglia & 11 & 10 & 8 & 7.33 \\
Basilicata & 9.5 & 9.67 & 8.75 & 10 \\
Calabria & 9.17 & 8.5 & 9.75 & 5 \\
Sicilia & 2 & 2.5 & 2.25 & 2 \\
Sardegna & 13.67 & 11 & 11.75 & 13 \\
\hline
\end{tabular}

Source: Authors' elaboration on ISTAT (2017).

weights with SMAA; (c) the multidimensional spatial inequality using the multidimensional Gini Index; (d) the analysis of within and between regions inequality, using the generalization of ANOGI.

\subsection{Ranking regions using equal weights}

The simplest composite index of mortality can be obtained by computing the arithmetic mean of the seventeen standardized mortality rates presented in Table 2. For convenience, we split the time series into 4 periods: beginning of the Nineties (1990-1995); the period before decentralisation (1996-2001); the period after decentralization (2002-2007); and the period of economic crisis (2008-2013).

Five groups of regions could be identified using this method: constant good performers (Trentino-Alto Adige, Emilia-Romagna, Toscana, Umbria, Marche, and Abruzzo); constant bad performers (Piemonte, Liguria, Campania, and Sicilia); regions that have improved performances over time (Valle d'Aosta, Lombardia, and Veneto); regions that have worsened (Molise, Puglia, and Calabria); and regions with no clear path (Friuli, Lazio, Basilicata, Sardegna). As previously discussed, however, the main drawback of this approach is the arbitrary nature of the weighting process, which simply gives all mortality rates the same weight. To overcome this assumption, we apply the SMAA approach to the whole set of possible vectors of weights. Table 3 shows the moving average of these regional ranks ${ }^{10}$.

\subsection{Ranking regions by SMAA}

The shortcoming of equal weights could be overcome by applying SMAA. This methodology produces a relevant amount of information, as the full dataset of ISTAT (2017) covers 20 regions in the intervals 1990-2003 and 2006-2013. For each of the 22 years of analysis, SMAA gives the probability of each region to have the $\mathrm{r}^{\text {th }}$ position in the ranking of the composite mortality index. ${ }^{11}$ In order to summarize the results, Figs. 1 and 2 show the cumulative

\footnotetext{
10 The ranks attached to each region in the period considered are available from the authors upon request.

11 To save space, the detailed results are available from the authors upon request. They report the number of occurrences, out of the 100,000 cases, a region achieves each possible ranking from 1 to 20 , taking a uniform distribution of the weights assigned to each of the 17 mortality rates.
}

rank acceptability indices for the upper and the lower side of the ranking, i.e., - respectively - what is the probability that each region is a bad or a good performer, given the whole set of feasible weights.

Fig. 1 shows the moving average of the downward cumulative rank acceptability index starting from rank 5 (i.e., we show $\left.b_{k}^{\leqslant 5}=\sum_{s=1}^{5} b_{k}^{s}\right)$. This is an approximation of the probability that the region has the fifth or a lower rank position, considering all the feasible convex linear combinations of standardized mortality rates. As can be seen, there have been few changes in the lowest five attainable ranks (i.e., the highest mortality rates). More precisely, there are two regions (Campania and Sicilia) that are the worst performers in the whole period, always having above an $80 \%$ probability to be in the lowest five ranks. Looking at the data in more detail, it emerges that Campania is constantly well above $90 \%$, which means that this region always has the highest composite indexes of mortality in more than $90 \%$ of cases.

On the opposite side, there are nine regions (Trentino-Alto Adige, Veneto, Emilia-Romagna, Toscana, Umbria, Marche, Abruzzo, Molise, and Sardegna) that constantly have less than a $20 \%$ probability to be in the lowest five ranks in the whole period. In the remaining regions, one can observe some cases of reductions of this probability (Lombardia, Valle d'Aosta, Friuli-V.G., and Basilicata) as well as cases of increasing it (Piemonte, Liguria, Lazio, and Calabria).

Fig. 2, rather, shows the moving average of the upward cumulative rank acceptability index of mortality for rank 16 or higher, i.e., for the best performer with the lowest composite mortality rate (i.e., we show $b_{k}^{\geqslant 16}=\sum_{s=16}^{20} b_{k}^{s}$ ). It can be seen that only one region (Marche) has more than an $80 \%$ probability to be at or above rank 16 in the whole period. On the opposite side, we can identify eight regions (Friuli V.G., Piemonte, Liguria, Lazio, Campania, Puglia, Calabria, and Sicilia) that constantly have less than a $20 \%$ probability to be among the best five regions, regardless of the weighting scheme. In the remaining regions, increases in the probability of being among the top five are observed in Lombardia, Veneto, Valle d'Aosta, Trentino-Alto Adige, and Umbria; reductions are observed in Emilia-Romagna, Toscana, Abruzzo, and Molise.

More generally, Figs. 2 and 3 show that in the period 19902013, there is a persistent spatial inequality in the Italian multidimensional health outcome. The Centre-North of the country was mainly a place with a lower composite mortality rate and still, the South was a place with a higher composite mortality rate, regardless of health reforms and decentralization. To strengthen this conclusion, one can stress that significant improvements can be observed only in specific regions of the North (Lombardia and Trentino), while more pronounced bad performances have involved some regions in the South (as Calabria).

According to these results, no convergence seems to emerge in health outcomes across regions over the 24 years of the analysis, with rather stable differences in mortality rates that are not significantly reduced in any period.

\subsection{The multidimensional spatial inequality}

The absence of convergence along the period analysed gives the opportunity to extend the investigation to the multidimensional spatial inequality using the set of multidimensional Gini indices as proposed in Greco et al. (2017) and reported in Eqs. (9) and (11). As previously explained, for each level of $l$ the higher $G^{\geq l}\left(G^{\leq l}\right)$ the more concentrated the probability for the regions to be over (under) the rank $l$ th in terms of the composite index of mortality. Accordingly, the higher $G^{\geq l}\left(G^{\leq l}\right)$ the greater the inequality in these cumulative probabilities across regions.

Table 4 reports $G^{\leq l}$ for the downward cumulative rank acceptability on the 4 th, 5th, and 6 th ranks, and $G^{\geq l}$ for the upward 

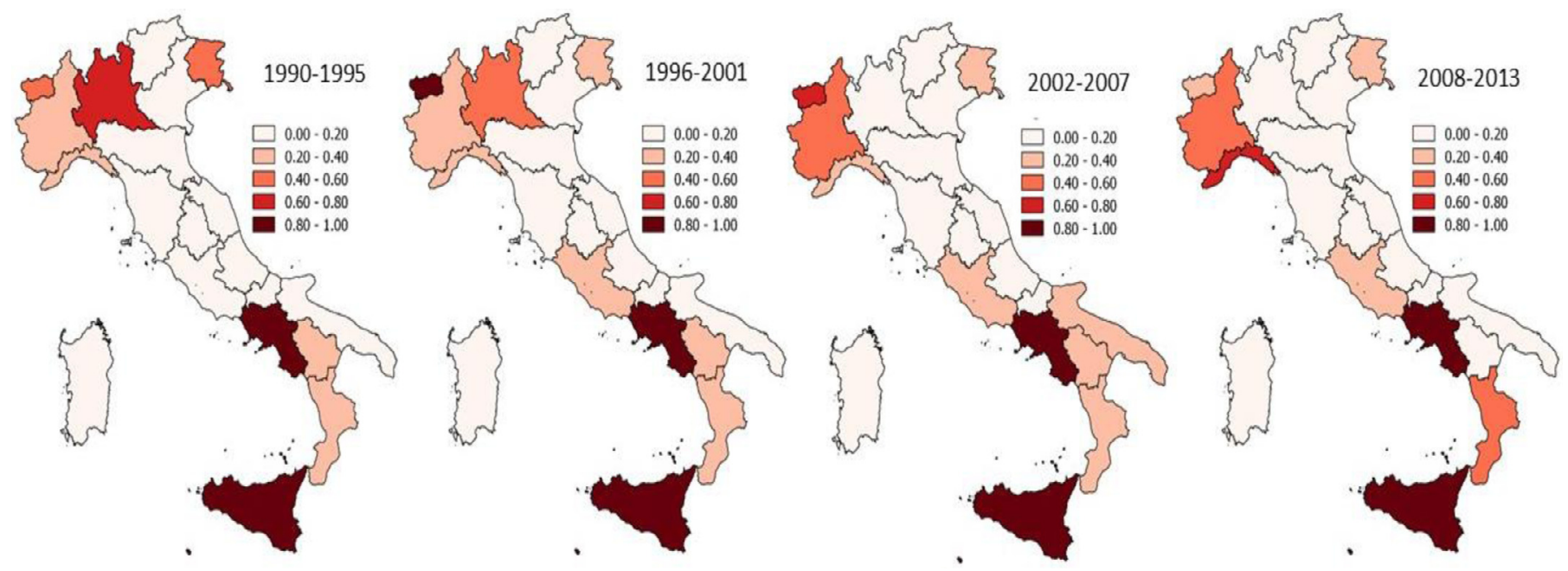

Fig. 1. Moving average of downward cumulative rank acceptability index of mortality for the rank 5 Fig. 2.
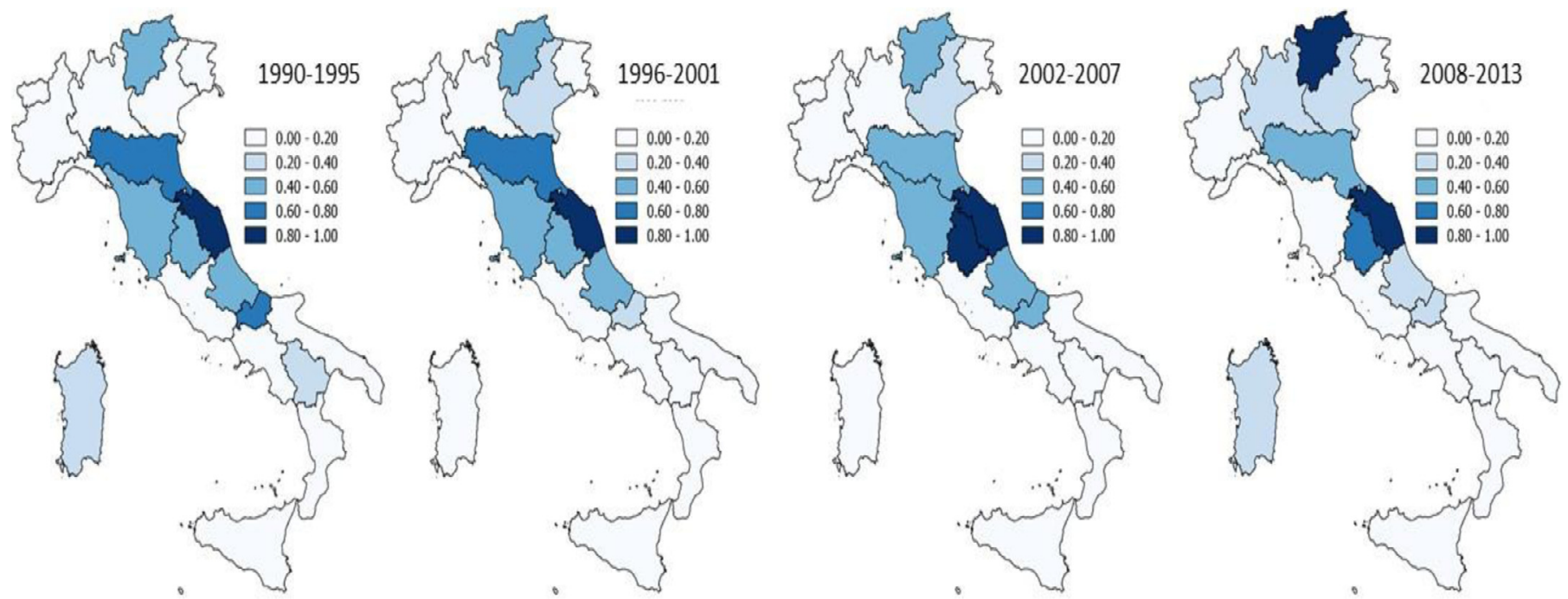

Fig. 2. Moving average of upward cumulative rank acceptability index of mortality for the rank 16 .
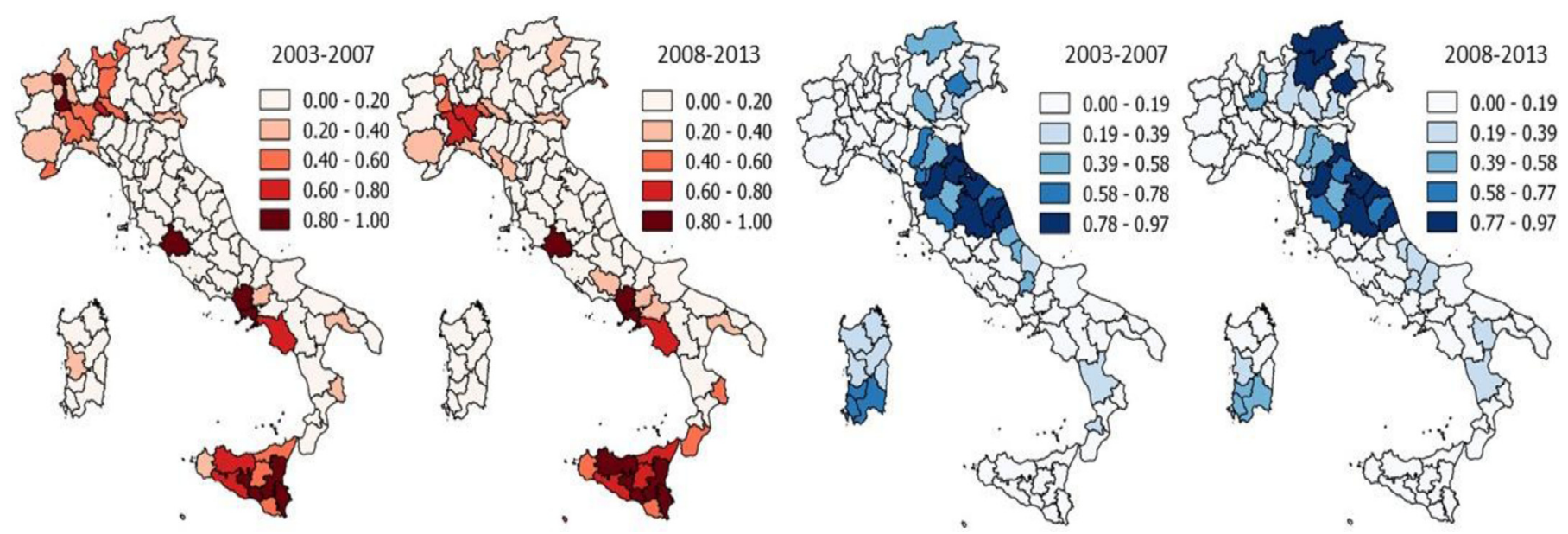

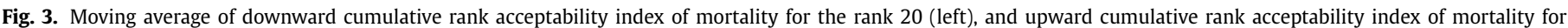
the rank 84 (right). 
Table 4

Multidimensional Gini indices.

\begin{tabular}{|c|c|c|c|c|c|c|}
\hline \multirow[t]{2}{*}{ Year } & \multicolumn{3}{|c|}{ Downward cumulative $(G \geq l)$} & \multicolumn{3}{|c|}{ Upward cumulative $(G \leq l)$} \\
\hline & Rank 4 & Rank 5 & Rank 6 & Rank 15 & Rank 16 & Rank 17 \\
\hline 1990 & 0.75 & 0.7 & 0.65 & 0.65 & 0.68 & 0.74 \\
\hline 1991 & 0.74 & 0.67 & 0.62 & 0.6 & 0.65 & 0.71 \\
\hline 1992 & 0.76 & 0.72 & 0.65 & 0.66 & 0.69 & 0.73 \\
\hline 1993 & 0.75 & 0.69 & 0.63 & 0.62 & 0.67 & 0.74 \\
\hline 1994 & 0.75 & 0.65 & 0.59 & 0.66 & 0.7 & 0.76 \\
\hline 1995 & 0.74 & 0.68 & 0.64 & 0.65 & 0.69 & 0.74 \\
\hline 1996 & 0.77 & 0.72 & 0.66 & 0.62 & 0.67 & 0.73 \\
\hline 1997 & 0.77 & 0.69 & 0.62 & 0.66 & 0.7 & 0.74 \\
\hline 1998 & 0.74 & 0.66 & 0.59 & 0.66 & 0.72 & 0.77 \\
\hline 1999 & 0.73 & 0.68 & 0.64 & 0.66 & 0.7 & 0.76 \\
\hline 2000 & 0.76 & 0.68 & 0.62 & 0.66 & 0.71 & 0.78 \\
\hline 2001 & 0.77 & 0.69 & 0.65 & 0.66 & 0.68 & 0.72 \\
\hline 2002 & 0.76 & 0.69 & 0.64 & 0.66 & 0.71 & 0.76 \\
\hline 2003 & 0.75 & 0.71 & 0.66 & 0.64 & 0.69 & 0.74 \\
\hline 2006 & 0.73 & 0.67 & 0.62 & 0.67 & 0.71 & 0.76 \\
\hline 2007 & 0.78 & 0.72 & 0.66 & 0.64 & 0.68 & 0.74 \\
\hline 2008 & 0.76 & 0.71 & 0.65 & 0.6 & 0.66 & 0.73 \\
\hline 2009 & 0.79 & 0.73 & 0.66 & 0.67 & 0.73 & 0.8 \\
\hline 2010 & 0.74 & 0.67 & 0.62 & 0.63 & 0.69 & 0.77 \\
\hline 2011 & 0.74 & 0.66 & 0.61 & 0.66 & 0.71 & 0.78 \\
\hline 2012 & 0.76 & 0.7 & 0.64 & 0.61 & 0.66 & 0.74 \\
\hline 2013 & 0.77 & 0.7 & 0.63 & 0.63 & 0.69 & 0.75 \\
\hline
\end{tabular}

Source: Authors' elaboration on ISTAT (2017).

cumulative rank acceptability on the 15th, 16th, and 17th ranks. As expected, inequality is lower when moving from rank 4 to 6 and from rank 17 to 15 , as both these movements imply a greater probability of each region of occupying at least the specific rank. The relevant information, however, is to observe inequality across years. Whatever rank is chosen, inequality is stable over the whole period, and high to any standard. For example, to grasp the implication of inequality of 0.75 at rank 17 (the highest) in 2013, one can observe that the same coefficient would be obtained by a hypothetical distribution where $75 \%$ of the regions have zero probability of being at rank 17 and the other regions have an equal probability to be there, which underlines a strong inequality in the opportunity to achieve that rank. Thus, regardless of the specific set of weights used, Table 4 reveals a strong inequality in both probabilities of being among the worst and among the best performers, which means that there are strong differences of health outcomes among regions.

\subsection{The multidimensional ANOGI}

A sub-set of our panel dataset with regional standardized mortality rates contains provincial data. In particular, provincial standardized mortality rates are available in ISTAT (2017) from 2003 to 2013. This feature of the dataset allows us to decompose the multidimensional inequality studied in the previous paragraph. Specifically, the traditional components of inequality among regions (between) and inequality within regions (at provincial level) may be separated and discussed. However, the decomposition of the Gini index does not contain only these two components, but appears with a residual that may have an interesting interpretation in the present analysis.

To this purpose, we use ANOGI as in Eqs. (12) and (14). In order to estimate total inequality, as well as the between and within components, we apply SMAA to 103 provinces. ${ }^{12}$ Fig. 3 reports the results by showing the moving average of both the upward and the downward cumulative rank acceptability indices of mortality

\footnotetext{
12 In 2017, there are 110 provinces in Italy, but until 2005 there were 103, in order to keep our panel balanced, we do not include in our analysis the provinces introduced in 2005 and 2009.
}

for the ranks 84 and 20, respectively. To this purpose, we split the panel in two periods: the post reform period (2003-2007); and the period of economic crisis (2008-2013). Four maps are drawn in Fig. 3: the two maps on the left side show the moving average of the downward cumulative rank acceptability index of mortality for rank 20; while the two maps on the right side show the moving average of the upward cumulative rank acceptability index of mortality for rank 84. It is worth recalling that a high value of the rank identifies the best performers, while the opposite is true for bad performers.

The main result of Fig. 3 is that the general territorial trends observed in Figs. 2 and 3 are confirmed by the analysis at provincial level. In particular, a bad performance in the Southern-West side of the country (Campania and Sicilia above all) and a good performance of the Northern-East is confirmed, and this involves the bulk of provinces in the corresponding regions. ${ }^{13}$ Moreover, over time an improvement of the performance of some Northern provinces emerges (for example, Trento and Bolzano), and a worsening in some provinces in Sardegna and Calabria. Again, convergence in health outcomes is hardly detectable after using a provincial analysis.

Table 5 shows the ANOGI of the downward cumulative rank acceptability index of mortality for rank 20. The first result is given by the level of total inequality as calculated by the overall Gini, which is slightly increasing over time, especially in the period of economic crisis. It is worth recalling that this indicator signals the concentration of probabilities to be among the worst 20 provinces in terms of health outcomes. Thus, a slight increase in concentration over time may suggest that there is a greater dispersion among the probabilities of being at the bottom of the rank.

Looking at the data in Table 5 one can note that the bulk of total inequality is due to an increase of inequality between regions, while the standard within inequality remains low and almost constant. A non-monotonic path is also shown by the impact of overlapping on within inequality. This means that, over time, the distribution of the provincial probabilities of being among the worst 20 was intertwined without any significant change.

To this purpose, Tables 6 and 7 report the matrices of $O_{j i}^{\leqslant 20}$, respectively for 2003 and 2013 only, ${ }^{14}$ obtained by the decomposition of the general overlapping index in Table 5, with rows indicating the base region $i$ and columns reporting each region $j$. By construction, each element of the main diagonal of this matrix equals 1. It is worth recalling that if no provinces in region $j$ lie in the range of the distribution of probabilities of provinces in region $i$, region $i$ could be defined a perfect stratum and $O_{j i}^{\leqslant 20}=0$.

Some characteristics of Table 6 are worth explaining. First, rows with missing values represent the cases in which all provinces of the baseline region have the same probability of being among the worst 20. This happens in Valle d'Aosta because it has just one province, and in Trentino, Umbria, Marche, Abruzzo, and Molise because all of their provinces have zero probability of being among the worst 20 in 2003. This implies that there is no distribution of probabilities to compare with other regions. Second, there are cases in which cells equal zero. As previously observed, these are cases where no member of the region $j$ lies in the distribution of probabilities of the members of region $i$, which means that region $i$ is a perfect stratum. In this context, being a perfect stratum means that, for the provinces of a given region, the probabilities of being among the worst 20 are extremely differentiated from

\footnotetext{
13 The territorial distribution of these performances is quite in line with previous estimates of health care efficiency in Italy (Giordano \& Tommasino, 2013; Patrizii \& Resce (2015)), although they use different outcome measures (Giordano \& Tommasino, 2013 use life expectancy; Patrizii and Resce (2015) use proxies of health service provided) and a different technique (Data Envelopment Analysis).

14 Details on the other years are available from the authors upon request.
} 
Table 5

ANOGI decomposition of multidimensional inequality for downward cumulative rank acceptability rank 20.

\begin{tabular}{llllll}
\hline Year & Total inequality & Standard within & Impact of overlapping on within & Between & Impact of overlapping on between \\
\hline 2003 & 0.73 & 0.029 & 0.222 & 0.595 & -0.115 \\
2006 & 0.738 & 0.029 & 0.311 & 0.568 & -0.17 \\
2007 & 0.737 & 0.028 & 0.242 & 0.59 & -0.123 \\
2008 & 0.738 & 0.032 & 0.322 & 0.554 & -0.17 \\
2009 & 0.759 & 0.029 & 0.246 & 0.629 & -0.145 \\
2010 & 0.751 & 0.032 & 0.278 & 0.59 & -0.149 \\
2011 & 0.752 & 0.02 & 0.194 & 0.642 & -0.104 \\
2012 & 0.761 & 0.026 & 0.271 & 0.61 & -0.147 \\
2013 & 0.758 & 0.026 & 0.248 & 0.621 & -0.139 \\
\hline
\end{tabular}

Source: Authors' elaboration on ISTAT (2017).

Table 6

Overlapping matrix for downward cumulative rank acceptability rank 20 by region, 2003.

\begin{tabular}{|c|c|c|c|c|c|c|c|c|c|c|c|c|c|c|c|c|c|c|c|c|}
\hline & PI & VA & LO & TR & VE & FR & LI & ER & $\mathrm{TU}$ & UM & MA & LA & $\mathrm{AB}$ & MO & CA & $\mathrm{AP}$ & BA & $\mathrm{CL}$ & SI & SA \\
\hline PI & 1 & 1.37 & 0.63 & 0 & 0.16 & 0.68 & 0.93 & 0.23 & 0.09 & 0 & 0 & 0.6 & 0 & 0 & 0.67 & 0.34 & 0.28 & 0.39 & 1.21 & 0.42 \\
\hline VA & NA & NA & NA & NA & NA & NA & NA & NA & NA & NA & NA & NA & NA & NA & NA & NA & NA & NA & NA & NA \\
\hline LO & 1.58 & 1.86 & 1 & 0 & 0.48 & 1.3 & 1.35 & 0.56 & 0.19 & 0 & 0 & 0.71 & 0 & 0 & 1.08 & 1.27 & 0.84 & 1.11 & 1.32 & 1.25 \\
\hline TR & NA & NA & NA & NA & NA & NA & NA & NA & NA & NA & NA & NA & NA & NA & NA & $\mathrm{NA}$ & NA & NA & NA & NA \\
\hline VE & 0.23 & 0 & 0.83 & 0.92 & 1 & 0.61 & 0.23 & 0.98 & 0.82 & 0.92 & 0.92 & 0.55 & 0.92 & 0.92 & 0 & 1.64 & 1.37 & 1.4 & 0 & 1.75 \\
\hline FR & 1.39 & 1.77 & 0.52 & 0.4 & 0.6 & 1 & 1.43 & 0.71 & 0.54 & 0.4 & 0.4 & 0.88 & 0.4 & 0.4 & 1.06 & 0.92 & 0.6 & 1.12 & 0.98 & 0.95 \\
\hline LI & 0.87 & 1.7 & 0.73 & 0.64 & 0.82 & 0.8 & 1 & 0.9 & 0.74 & 0.64 & 0.64 & 0.64 & 0.64 & 0.64 & 0.34 & 1.28 & 0.96 & 1.23 & 0 & 1.28 \\
\hline ER & 0.39 & 0 & 0.76 & 0.83 & 1.05 & 1 & 0.57 & 1 & 0.75 & 0.83 & 0.83 & 0.79 & 0.83 & 0.83 & 0 & 1.71 & 1.28 & 1.29 & 0 & 1.63 \\
\hline $\mathrm{TU}$ & 0.5 & 0 & 1.09 & 1 & 1.29 & 1.25 & 0.75 & 1.33 & 1 & 1 & 1 & 1 & 1 & 1 & 0.4 & 2 & 1.5 & 1.6 & 0 & 2 \\
\hline UM & NA & NA & NA & NA & NA & NA & NA & NA & NA & NA & NA & NA & NA & NA & NA & NA & NA & NA & NA & NA \\
\hline MA & NA & NA & NA & NA & NA & NA & NA & NA & NA & NA & NA & NA & NA & NA & NA & NA & NA & NA & NA & NA \\
\hline LA & 1.47 & 1.74 & 1.34 & 0.33 & 0.61 & 1.17 & 1.39 & 0.7 & 0.47 & 0.33 & 0.33 & 1 & 0.33 & 0.33 & 0.96 & 1.18 & 0.82 & 1.26 & 1.35 & 1.14 \\
\hline $\mathrm{AB}$ & NA & NA & NA & NA & NA & NA & NA & NA & NA & NA & NA & NA & NA & NA & NA & NA & NA & NA & NA & NA \\
\hline MO & NA & NA & NA & NA & NA & NA & NA & NA & NA & NA & NA & NA & NA & NA & NA & NA & NA & NA & NA & NA \\
\hline $\mathrm{CA}$ & 0.86 & 1.06 & 0.84 & 0 & 0 & 0.41 & 0.53 & 0 & 0.11 & 0 & 0 & 0.62 & 0 & 0 & 1 & 0 & 0 & 0.21 & 1.52 & 0 \\
\hline $\mathrm{AP}$ & 0.23 & 0 & 0.54 & 0 & 0.26 & 0.19 & 0 & 0.2 & 0 & 0 & 0 & 0.21 & 0 & 0 & 0 & 1 & 0.92 & 0.57 & 0 & 0.92 \\
\hline BA & 0.25 & 0 & 0.91 & 1 & 0.71 & 0.25 & 0.25 & 0.89 & 0.9 & 1 & 1 & 0.6 & 1 & 1 & 0 & 0.8 & 1 & 1.2 & 0 & 1 \\
\hline $\mathrm{CL}$ & 0.85 & 1.75 & 0.61 & 0 & 0.48 & 0.84 & 0.87 & 0.55 & 0.17 & 0 & 0 & 0.46 & 0 & 0 & 0.35 & 1.29 & 0.8 & 1 & 0 & 1.31 \\
\hline SI & 0 & 0 & 0.57 & 0 & 0 & 0.39 & 0 & 0 & 0 & 0 & 0 & 0.45 & 0 & 0 & 0.42 & 0 & 0 & 0 & 1 & 0 \\
\hline SA & 0.13 & 0 & 0.48 & 0 & 0.19 & 0.34 & 0 & 0.33 & 0 & 0 & 0 & 0.21 & 0 & 0 & 0 & 1.23 & 0.8 & 0.8 & 0 & 1 \\
\hline
\end{tabular}

Source: Authors' elaboration on ISTAT (2017); Notes: PI = Piemonte, VA = Valle d'Aosta, LO = Lombardia, TR $=$ Trentino A.A., VE $=$ Veneto, FR $=$ Friuli V.G., LI = Liguria, $\mathrm{ER}=$ Emilia Romagna, $\mathrm{TU}=$ Toscana, $\mathrm{UM}=$ Umbria, $\mathrm{MA}=$ Marche, $\mathrm{LA}=$ Lazio, $\mathrm{AB}=$ Abruzzo, $\mathrm{MO}=\mathrm{Molise}, \mathrm{CA}=\mathrm{Campania}, \mathrm{AP}=\mathrm{Puglia}, \mathrm{BA}=\mathrm{Basilicata}, \mathrm{CL}=\mathrm{Calabria}$, SI $=$ Sicilia, $\mathrm{SA}=$ Sardegna

the probabilities attached to other provinces in other regions. Excluding the regions with missing values, the most frequent cases of perfect stratum are associated to Campania, Puglia, Sicilia and Sardegna. This result suggests that a non-negligible number of provinces in the South of Italy represents a 'world apart' with respect to the health outcomes. Looking at the elementary data, indeed, confirms that many provinces in these regions have extremely high probabilities of being in the lowest ranks.

Third, the territorial high stratification is also confirmed by looking at sufficiently low values of $O_{j i}^{\leqslant 20}$, which denotes a high level of stratification. Reading Table 6 by rows, it emerges that, on average, $O_{j i}^{\leqslant 20}<0.4$ again in Campania, Puglia, Sicilia and Sardegna. On the opposite side, a relatively low degree of stratification (i.e., $O_{j i}^{\leqslant 20}>0.4$ ) is mainly found in Northern regions (with the exceptions of Basilicata and Lazio in the South and Centre respectively). The combination of these two results suggests that usually there are relatively more provinces of the poorest part of the country in the range of the distribution of the richest part than there are provinces in the richest part in the range of the distribution of the poorest part. In other words, there are relatively more good performer provinces in the bad performer regions than there are bad performer provinces in the good performer regions. Consider, for example, the relationship between Lombardia (L) and Puglia (A). Taking $\mathrm{L}$ as a baseline, $O_{A L}^{\leq 20}=1.27$, while taking $\mathrm{A}$ as a baseline $O_{L A}^{\leqslant 20}=0.54$. This means that there are more provinces of Puglia overlapping the distribution of provinces in Lombardia than there are provinces of Lombardia overlapping the distribution of Puglia.
Finally, there are cases where $O_{j i}^{\leqslant 20} \geqslant 1.5$, as in the case of using Toscana as a baseline with respect to Basilicata, Calabria, Puglia, Sardegna. These cases are particularly interesting, as high values of the overlapping term suggest that the bulk of the observations of distribution $j$ that are located in the range of distribution $i$ are concentrated around the mean of the distribution $i$. In particular, $O_{j i}^{\leqslant 20}=2$ in the case of Puglia and Sardegna with Toscana as a baseline. It means that all probabilities of the provinces of Puglia and Sardegna are included between the lowest and the highest probability of the provinces of Toscana. More specifically, Puglia and Sardegna split the probabilities of Toscana in two parts, one above and one below the mean.

Table 7 reports the same matrix for the downward cumulative rank in 2013. Only marginal changes are in fact visible. Many regions that were a perfect stratum in 2013, still are (Campania, Sardegna, Sicilia). Puglia seems to have left this characteristic, while Calabria has gained it. On average, high levels of stratification mainly appear in the regions of the South, which means that their probabilities of being in the lowest rank are not shared by many other regions. Moreover, it still holds that there are more provinces of the poorest regions overlapping the distribution of provinces in the richest regions than there are provinces of the richest regions overlapping the distribution of the poorest ones. Thus, overall, moving from 2003 to 2013 has only marginally improved the convergence of provinces across the country in terms of health outcomes.

Comparing these results with the information reported in Table 5 suggests that while the standard within inequality is low, 
Table 7

Overlapping matrix for downward cumulative rank acceptability rank 20 by region, 2013.

\begin{tabular}{|c|c|c|c|c|c|c|c|c|c|c|c|c|c|c|c|c|c|c|c|c|}
\hline & PI & VA & LO & TR & $\mathrm{VE}$ & FR & LI & ER & TU & UM & MA & LA & $\mathrm{AB}$ & MO & $\mathrm{CA}$ & $\mathrm{AP}$ & BA & $\mathrm{CL}$ & SI & SA \\
\hline PI & 1 & 1.12 & 0.79 & 0.19 & 0.83 & 1.25 & 1.14 & 0.28 & 0.4 & 0.19 & 0.19 & 0.53 & 0.6 & 0.65 & 0.68 & 0.7 & 0.65 & 1.64 & 0.77 & 0.48 \\
\hline VA & NA & NA & NA & NA & NA & NA & NA & NA & NA & NA & NA & NA & NA & NA & NA & NA & NA & NA & NA & NA \\
\hline LO & 0.99 & 1.37 & 1 & 0.57 & 1.06 & 0.97 & 1.37 & 0.9 & 0.92 & 0.57 & 0.57 & 0.66 & 1.18 & 0.97 & 0 & 1.27 & 0.97 & 1.52 & 0.19 & 1.26 \\
\hline TR & NA & NA & NA & NA & NA & NA & NA & NA & NA & NA & NA & NA & NA & NA & NA & NA & NA & NA & NA & NA \\
\hline VE & 1.04 & 1.51 & 0.98 & 0.57 & 1 & 0.95 & 1.52 & 0.99 & 0.96 & 0.57 & 0.57 & 0.72 & 1.32 & 1.04 & 0 & 1.36 & 1.04 & 1.56 & 0.17 & 1.51 \\
\hline FR & 0.77 & 0.85 & 0.86 & 0.43 & 0.88 & 1 & 1.25 & 0.62 & 0.66 & 0.43 & 0.43 & 0.76 & 0.75 & 0.64 & 0.66 & 0.9 & 0.64 & 1.43 & 0.35 & 0.85 \\
\hline LI & 1.07 & 1.89 & 0.69 & 0 & 0.54 & 0.95 & 1 & 0.22 & 0.39 & 0 & 0 & 0.2 & 0.72 & 0.95 & 0 & 1.15 & 0.95 & 1.52 & 0.21 & 0.5 \\
\hline ER & 0.09 & 0 & 0.47 & 0.7 & 0.5 & 0.18 & 0.43 & 1 & 0.76 & 0.7 & 0.7 & 0.75 & 0.59 & 0.35 & 0 & 0.42 & 0.35 & 0 & 0 & 0.83 \\
\hline TU & 1.63 & 1.83 & 1.13 & 0.46 & 1.12 & 1.44 & 1.67 & 0.89 & 1 & 0.46 & 0.46 & 1.36 & 1.26 & 1.15 & 1.04 & 1.47 & 1.15 & 1.78 & 1.54 & 1.43 \\
\hline UM & NA & NA & NA & NA & NA & NA & NA & NA & NA & NA & NA & NA & NA & NA & NA & NA & NA & NA & NA & NA \\
\hline MA & NA & NA & NA & NA & NA & NA & NA & NA & NA & NA & NA & NA & NA & NA & NA & NA & NA & NA & NA & NA \\
\hline LA & 1.53 & 1.9 & 1.06 & 0.32 & 1.04 & 1.33 & 1.74 & 0.74 & 0.79 & 0.32 & 0.32 & 1 & 1.18 & 1.11 & 1 & 1.45 & 1.11 & 1.9 & 0.96 & 1.26 \\
\hline $\mathrm{AB}$ & 0.78 & 1.96 & 0.63 & 0.34 & 0.52 & 0.09 & 0.83 & 0.72 & 0.67 & 0.34 & 0.34 & 0.61 & 1 & 1.15 & 0 & 1.12 & 1.15 & 0.39 & 0 & 1.17 \\
\hline MO & 0.63 & 0 & 0.64 & 1 & 0.71 & 0.25 & 1 & 1.44 & 1.2 & 1 & 1 & 1 & 1.25 & 1 & 0 & 1.4 & 1.5 & 0 & 0 & 2 \\
\hline CA & 0.45 & 0 & 0 & 0 & 0 & 0.45 & 0 & 0 & 0.15 & 0 & 0 & 0.65 & 0 & 0 & 1 & 0 & 0 & 0 & 1.4 & 0 \\
\hline AP & 0.65 & 1.59 & 0.62 & 0.29 & 0.44 & 0.47 & 0.56 & 0.49 & 0.46 & 0.29 & 0.29 & 0.4 & 0.9 & 0.94 & 0 & 1 & 0.98 & 0.32 & 0 & 1 \\
\hline BA & 0.63 & 0 & 0.64 & 1 & 0.71 & 0.25 & 1 & 1.44 & 1.2 & 1 & 1 & 1 & 1.25 & 0.5 & 0 & 1 & 1 & 0 & 0 & 2 \\
\hline $\mathrm{CL}$ & 0.32 & 0 & 0.32 & 0 & 0.34 & 0.63 & 0.52 & 0 & 0.14 & 0 & 0 & 0 & 0.24 & 0 & 0 & 0.19 & 0 & 1 & 0.17 & 0 \\
\hline SI & 0.48 & 0 & 0.19 & 0 & 0.15 & 0.6 & 0.52 & 0 & 0.04 & 0 & 0 & 0.49 & 0 & 0 & 0.7 & 0 & 0 & 0.42 & 1 & 0 \\
\hline SA & 0.22 & 0 & 0.14 & 0 & 0 & 0 & 0.38 & 0.5 & 0.48 & 0 & 0 & 0.6 & 0.81 & 0 & 0 & 0.65 & 0 & 0 & 0 & 1 \\
\hline
\end{tabular}

Source: Authors' elaboration on ISTAT (2017); Notes: PI = Piemonte, VA = Valle d'Aosta, LO = Lombardia, TR = Trentino A.A., VE = Veneto, FR = Friuli V.G., LI = Liguria,

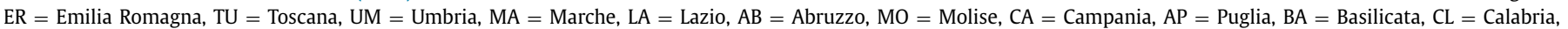
$\mathrm{SI}=$ Sicilia, $\mathrm{SA}=$ Sardegna.

Table 8

ANOGI decomposition of multidimensional inequality for upward cumulative rank acceptability rank 84 .

\begin{tabular}{llllll}
\hline Year & Total inequality & Standard within & Impact of overlapping on within & Between & Impact of overlapping on between \\
\hline 2003 & 0.759 & 0.029 & 0.325 & 0.615 & -0.210 \\
2006 & 0.762 & 0.029 & 0.308 & 0.625 & -0.200 \\
2007 & 0.755 & 0.029 & 0.357 & 0.581 & -0.213 \\
2008 & 0.747 & 0.033 & 0.396 & 0.546 & -0.228 \\
2009 & 0.749 & 0.030 & 0.324 & 0.585 & -0.190 \\
2010 & 0.756 & 0.029 & 0.357 & 0.595 & -0.225 \\
2011 & 0.751 & 0.034 & 0.300 & 0.572 & -0.155 \\
2012 & 0.748 & 0.034 & 0.371 & 0.523 & -0.179 \\
2013 & 0.750 & 0.033 & 0.349 & 0.565 & -0.198 \\
\hline
\end{tabular}

Source: Authors' elaboration on ISTAT (2017).

its value becomes greater because the distributions of probabilities of provinces has some degree of overlapping, even though a significant degree of stratification occurs in the regions of the South.

In the same vein, Table 8 reports the results for the upward cumulative rank. The path of the various components of the Gini index is almost the same as in Table 5. Total inequality is stable and high between 2003 and 2013, which means that there is a great concentration among the probabilities of being at the top ranks. As before, the bulk of total inequality is given by inequality between regions, even with a declining weight. On the other hand, within inequality shows a small increase over time. Thus, while regions have a weak tendency to converge, on average, there is some evidence of a greater inequality among provinces within regions, for example because some provinces converge with others beyond the regional borders.

\section{Conclusions}

This paper introduces an innovative measure of the regional outcome of the Italian National Health Care Service. We estimate a composite index of mortality by the combination of the seventeen mortality rates at regional and provincial level. Our $\mathrm{CI}$ of mortality is given by the sum of the standardized mortality rates for seventeen diseases, weighed by a random set of weights from a uniform distribution. We employ, for the first time in literature related to health performance, the SMAA approach, which allows to summarize the multidimensional health outcome without any assumption about the health care preferences (needs) of people.
Furthermore, we measure the spatial segregation using the multidimensional generalization of the Gini index presented in Greco et al. (2017), and we introduce the multidimensional generalization of the ANOGI to disentangle between and within inequality.

Our results show that there is a pervasive and persistent spatial segregation in the health outcome. In particular, we observe a bad performer area in the Southern-West side of the country (Campania and Sicilia above all), and a good performer area in the NorthEast. Moreover, it emerges that in the period 1990-2013 there was improvement in some Northern regions (Lombardia, Trento and Bolzano in particular), and a worsening in some Southern regions (Sardegna and Calabria). The inequality of the distribution of probabilities is high by any standard, both for the downward and for the upward cumulative rank, with the bulk of this inequality given by inequality between regions. This feature, to some extent, contradicts the constitutional provision of providing the right for essential levels of care over the whole country.

From a general perspective, the results show that some regions of the South still appear to be relatively stratified with respect to the rest of the country and to other regions, and that some provinces converge beyond the regional borders, as also suggested by the increase in within inequality especially when considering the top ranks. Regional disparities seem to be persistent over time, and also the decentralisation reforms that have given more organizational and spending power to the regions, seems to have altered this pattern. This study provides evidence that the general positive effect of decentralization on health performance in Italy, mainly found in Infant Mortality Rates (Cavalieri \& Ferrante, 2016) 
has not involved all the dimensions of health, it has not involved all the regions, and to some extent, it came at the cost of increasing the gap between North and South of the country.

\section{Funding}

Raffaele Lagravinese acknowledges financial support from the Regione Puglia (Future in Research Project). The research carried out in this paper is part of a wider project on 'Crisi economica, distribuzione dei redditi e criteri di accesso alle politiche di assistenza' (R876/2015).

\section{Supplementary material}

Supplementary material associated with this article can be found, in the online version, at doi:10.1016/j.ejor.2018.11.009.

\section{References}

Aertsen, W., Kint, V., Van Orshoven, J., \& Muys, B. (2011). Evaluation of modelling techniques for forest site productivity prediction in contrasting ecoregions using stochastic multicriteria acceptability analysis (SMAA). Environmental Modelling $\mathcal{E}$ Software, 26(7), 929-937.

Angilella, S., Corrente, S., Greco, S., \& Sł owiński, R. (2016). Robust ordinal regression and stochastic multiobjective acceptability analysis in multiple criteria hierarchy process for the Choquet integral preference model. Omega, 63, 154-169.

Angilella, S., \& Mazzù, S. (2015). The financing of innovative SMEs: A multicriteria credit rating model European Journal of Operational Research, 244(2) 540-554.

Bottero, M., Ferretti, V., Figueira, J. R., Greco, S., \& Roy, B. (2015). Dealing with a multiple criteria environmental problem with interaction effects between criteria through an extension of the electre III method. European Journal of Operational Research, 245(3), 837-850.

Cappellaro, G., Fattore, G., \& Torbica, A. (2009). Funding health technologies in decentralized systems: A comparison between italy and spain. Health Policy, 92(2), 313-321.

Carinci, F., Caracci, G., Di Stanislao, F., \& Moirano, F. (2012). Performance measurement in response to the Tallinn charter: Experiences from the decentralized italian framework. Health Policy, 108(1), 60-66.

Cavalieri, M., \& Ferrante, L. (2016). Does fiscal decentralization improve health outcomes? Evidence from infant mortality in italy. Social Science \& Medicine, 164, 74-88.

Cherchye, L., Moesen, W., Rogge, N., \& Van Puyenbroeck, T. (2007). An introduction to 'benefit of the doubt' composite indicators. Social Indicators Research, 82(1), $111-145$.

Cohen, S., Doumpos, M., Neofytou, E., \& Zopounidis, C. (2012). Assessing financial distress where bankruptcy is not an option: An alternative approach for local municipalities. European Journal of Operational Research, 218(1), 270-279.

Costanza, R., Daly, L., Fioramonti, L., Giovannini, E., Kubiszewski, I., Mortensen, L. F., \& Wilkinson, R. (2016). Modelling and measuring sustainable wellbeing in connection with the UN sustainable development goals. Ecological Economics, 130, 350-355.

Deaton, A., \& Lubotsky, D. (2003). Mortality, inequality and race in american cities and states. Social Science \& Medicine, 56(6), 1139-1153.

Doumpos, M., Hasan, I., \& Pasiouras, F. (2017). Bank overall financial strength: Islamic versus conventional banks. Economic Modelling, 64, 513-523.

Ferrario, C., \& Zanardi, A. (2011). Fiscal decentralization in the italian NHS: What happens to interregional redistribution? Health Policy, 100(1), 71-80.

Floridi, M., Pagni, S., Falorni, S., \& Luzzati, T. (2011). An exercise in composite indicators construction: Assessing the sustainability of Italian regions. Ecologica economics, 70(8), 1440-1447.

Frick, J. R., Goebel, J., Schechtman, E., Wagner, G. G., \& Yitzhaki, S. (2006). Using analysis of Gini (ANOGI) for detecting whether two subsamples represent the same universe. Sociological Methods and Research, 34(4), 427-468.

Giordano, R., \& Tommasino, P. (2013). Public-sector efficiency and political culture. FinanzArchiv: Public Finance Analysis, 69(3), 289-316.

Greco, S., Figueira, J., \& Ehrgott, M. (2016). Multiple criteria decision analysis. New York: Springer.
Greco, S., Ishizaka, A., Matarazzo, B., \& Torrisi, G. (2017). Stochastic multi-attribute acceptability analysis (SMAA): An application to the ranking of italian regions. Regional Studies, 1-16.

Greco, S., Ishizaka, A., Tasiou, M., \& Torrisi, G. (2018). On the methodological framework of composite indices: a review of the issues of weighting, aggregation, and robustness. In Social indicators research (pp. 1-34).

Ishizaka, A., \& Nemery, P. (2013). Multi-criteria decision analysis: methods and software. John Wiley \& Sons.

ISTAT (2017). Health for All - Italia. Roma, ISTAT.

Julious, S. A., Nicholl, J., \& George, S. (2001). Why do we continue to use standardized mortality ratios for small area comparisons? Journal of Public Health, 23(1) 40-46.

Lagravinese, R., Liberati, P., \& Sacchi, A. (2018). The growth and variability of regional taxes: An application to italy. Regional Studies, 52(3), 416-429.

Lahdelma, R., Hokkanen, J., \& Salminen, P. (1998). SMAA-stochastic multiobjective acceptability analysis. European Journal of Operational Research, 106(1), 137-143.

Lahdelma, R., \& Salminen, P. (2001). SMAA-2: Stochastic multicriteria acceptability analysis for group decision making. Operations Research, 49(3), 444-454.

Lahdelma, R., Salminen, P., \& Hokkanen, J. (2002). Locating a waste treatment facility by using stochastic multicriteria acceptability analysis with ordinal criteria. European Journal of Operational Research, 142(2), 345-356.

Liberati, P. (2003). Fiscal federalism and national health standards in Italy: Implications for redistribution. $i$ sistemi di welfare tra decentramento regionale e integrazione europea (pp. 241-273). Franco Angeli.

Liberati, P. (2015). The world distribution of income and its inequality, 1970-2009. Review of Income and Wealth, 61(2), 248-273.

Medin, E., Goude, F., Melberg, H. O., Tediosi, F., Belicza, E., \& Peltola, M. (2015). European regional differences in all-cause mortality and length of stay for patients with hip fracture. Health economics, 24(S2), 53-64.

Menou, A., Benallou, A., Lahdelma, R., \& Salminen, P. (2010). Decision support for centralizing cargo at a Moroccan airport hub using stochastic multicriteria acceptability analysis. European Journal of Operational Research, 204(3), 621-629.

Milanovic, B., \& Yitzhaki, S. (2002). Decomposing world income distribution: Does the world have a middle class? Review of Income and Wealth, 2, 155-178.

Nardo, M., Saisana, M., Saltelli, A., Tarantola, S., Hoffman, A., \& Giovannini, E. (2008) Handbook on constructing composite indicators. Paris: OECD-JRC.

OECD (2016). Health at a glance: Europe 2016: State of health in the EU cycle. Paris: OECD Publishing.

Or, Z. (2001). Exploring the effects of health care on mortality across OECD countries. In OECD labour market and social policy occasional papers, no. 46. Paris: OECD Publishing.

Patrizii, V., Pettini, A., \& Resce, G. (2017). The cost of well-being. Social Indicators Research, 133(3), 985-1010.

Patrizii, V., \& Resce, G. (2015). Public sector contribution to competitiveness. Italian Economic Journal, 1(3), 401-443.

Permanyer, I. (2011). Assessing the robustness of composite indices rankings. Review of Income and Wealth, 57(2), 306-326.

Porcelli, F. (2014). Electoral accountability and local government efficiency: Quasiexperimental evidence from the italian health care sector reforms. Economics of Governance, 15(3), 221-251.

Pyatt, G. (1976). On the interpretation and disaggregation of Gini coefficients. The Economic Journal, 86(342), 243-255.

Savaglio, E. (2006). Three approaches to the analysis of multidimensional inequality. In F. Farina, \& E. Savaglio (Eds.), Inequality and economic integration ( $p p$. 264-277). London: Routledge.

Sen, A. (1998). Mortality as an indicator of economic success and failure. The Economic Journal, 108(446), 1-25.

Tervonen, T., \& Lahdelma, R. (2007). Implementing stochastic multicriteria acceptability analysis. European Journal of Operational Research, 178, 500-513.

Turati, G. (2013). The italian servizio sanitario nazionale: A renewing tale of lost promises. In Federalism and decentralization in European health and social care (pp. 47-66). UK: Palgrave Macmillan.

Weymark, J. A. (2006). The normative approach to the measurement of multidimensional inequality. In F. Farina, \& E. Savaglio (Eds.), Inequality and economic integration (pp. 303-328). London: Routledge.

Yitzhaki, S. (1994). Economic distance and overlapping of distributions. Journal of Econometrics, 61(1), 147-159.

Yitzhaki, S., \& Lerman, R. (1991). Income stratification and income inequality. Review of Income and Wealth, 37, 313-329.

Yitzhaki, S., \& Schechtman, E. (2009). The "melting pot" : A success story? Journal of Economic Inequality, 7, 137-151.

Yitzhaki, S., \& Schechtman, E. (2013). The Gini methodology - A primer on a statistical methodology. New York: Springer. 